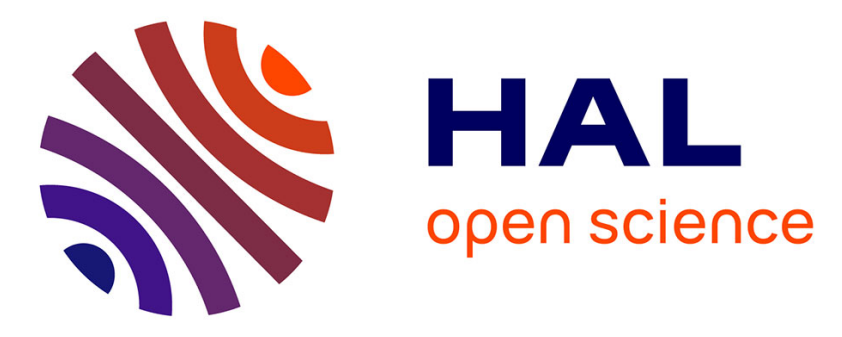

\title{
Enhancing Regional Digital Preparedness on Natural Hazards to Safeguard Business Resilience in the Asia-Pacific
}

\author{
Wei-Sen Li, Yanling Lee, Kenji Watanabe
}

\section{To cite this version:}

Wei-Sen Li, Yanling Lee, Kenji Watanabe. Enhancing Regional Digital Preparedness on Natural Hazards to Safeguard Business Resilience in the Asia-Pacific. 1st International Conference on Information Technology in Disaster Risk Reduction (ITDRR), Nov 2016, Sofia, Bulgaria. pp.170-182, 10.1007/978-3-319-68486-4_14. hal-03213114

\author{
HAL Id: hal-03213114 \\ https://hal.inria.fr/hal-03213114
}

Submitted on 30 Apr 2021

HAL is a multi-disciplinary open access archive for the deposit and dissemination of scientific research documents, whether they are published or not. The documents may come from teaching and research institutions in France or abroad, or from public or private research centers.
L'archive ouverte pluridisciplinaire HAL, est destinée au dépôt et à la diffusion de documents scientifiques de niveau recherche, publiés ou non, émanant des établissements d'enseignement et de recherche français ou étrangers, des laboratoires publics ou privés. 


\title{
Enhancing Regional Digital Preparedness on Natural Hazards to Safeguard Business Resilience in the Asia-Pacific
}

\author{
Yanling Lee ${ }^{1}$, Kenji Watanabe ${ }^{2}$ and Wei-Sen $\mathrm{Li}^{1}$ \\ ${ }^{1}$ National Science and Technology Center for Disaster Reduction, Taipei, Taiwan \\ li.weisenencdr.nat.gov.tw \\ ${ }^{2}$ Nagoya Institute of Technology, Nagoya, Japan \\ sophiancdregmail.com
}

\begin{abstract}
In March 2015, the Sendai Framework for Disaster Risk Reduction (SFDRR) enforced during the Third UN World Conference on Disaster Risk Reduction. The SFDRR does not just succeed spirits and values of the Hyogo Framework for Action, but also leads the world entering a new phase of disaster risk reduction through stakeholders at national, regional and global levels. Among all regions around the world, the Asia-Pacific is the most vulnerable to natural hazards and climate changes. Disaster risk reduction (DRR) is critical concerned in terms of national security, economic quality growth, environmental sustainability and people's livelihoods. For regional consideration, a large-scale disaster could direct and indirect impact more than one countries due to the damaged or interrupted supply chain. Therefore, regional efforts on DRR have been a focal issue. After the 2011 Great Japan Earthquakes and Tsunami, an emergent global trend of developing strategy to strengthen global value chain or supply chain resilience via business continuity planning (BCP) approach engages the small and medium enterprises (SMEs) and the multinational or international corps to limit interruption and enhance cross border manufacturing, trade and investments. Base on the practical DRR project implementations and experiences over the years, the Asia-Pacific Economic Cooperation (APEC) identifies several key factors to promote disaster resilience in business sectors. The SFDRR also encourages innovation, science and technology DRR approaches i.e. big data and open day can help sharing the value-added information on enhancing capacity building of SMEs' disaster resilient capacity via decent risk communication tools for raising the risk awareness and level of digital preparedness. This paper describes to what extend the business sectors involved in and how to safeguard the cross-border trade and investments with safer and smarter regional strategies in the digital age with large-scale disasters.
\end{abstract}

Keywords: Business Continuity Plan (BCP), Regional Digital Preparedness, Small and Medium Enterprises (SMEs), Big Data, Asia-Pacific Economic Cooperation (APEC). 


\section{$1 \quad$ High Vulnerabilities of Natural Hazards in the Asia-Pacific}

Asia is one of the most competitive marketplaces in the world. Within the region, the struggle on compromising profits on supply chain interruption while disasters. Thus, the fruitful profits come from the significant economy growth via highly supply chain integrated operations in the region of high vulnerabilities and exposures to natural hazards of Asia. From 2003-2013, the annual economic loss reach up to some US\$68 billion in the Asia-Pacific Region [1]. The critical issues drawn by the average loses call upon the action plans for enhancing disaster resilience at regional level. Disasters not just adversely impact people's livelihoods, but also could interrupt regional or even global business operations, due to the direct impact on commodity shortage. In today's highly globalized and regionalized integration on production activities, more and more business units take advantages to governing global value chains for pursuing ultimate profitability, i.e. to navigate cross-border business networks of public and private sectors to coordinate the manufacturing, operations, financing, marketing and logistics on multiple product line suppliers and subcontractors in order to outreach the end consumers in various parts of the world.

Asia-Pacific Economic Cooperation (APEC) is one of a kind Asia-Pacific economic forum target to uphold the regional economic growth and prosperity. Twenty-one APEC member economies occupied 44 percent of global trade ( $\$ 16.8$ trillion) and 53 percent of world real GDP in purchasing power parity (PPP) terms ( $\$ 35.8$ trillion) created by 40 percent of world population ( 2.7 billion people) [2], (see Fig.1).

\section{Regional and Global Efforts on Promoting Business Continuity Since 2011 in the Asia-Pacific}

Business Continuity Plan (BCP) is not an emergent idea in business management. A conventional BCP usually copes with threats of financial crisis, information interruptions and manufacturing accidents, instead of natural hazards. Learning experiences from the 2011 Great Japan Earthquakes and Tsunami, and the Floods in Thailand that clearly identify high vulnerabilities in business sectors and reminds business owners to develop traditional business continuity plan and include adverse impacts caused by natural disasters. Though interruptions, originated from business operations, cash flows or inconsistency of information, have been taken into serious consideration, but those setbacks are listed as daily-basis check-up items and most business units has plans to respond to the emergency by Standard Operation Procedures (SOPs). However, after a major disaster, chain effects of business interruptions would probable affect the whole supply chain domestically or even internationally. For example, the severe floods in Thailand caused ripple effects of business interruptions to automobile production line and PC manufacture activities in the Asia-Pacific. Likewise, the 2011 earthquakes and tsunami in Japan also brought down ICT industry and auto parts. Counting casualties and losses aftermath, economic loss exceeded 1.7 Billion Yen (equal to $3.4 \%$ GDP of Japan), death toll number (or missing) around twenty thousand, direct loss (including damaged households, manufacturing utilities, highways and bridges). 


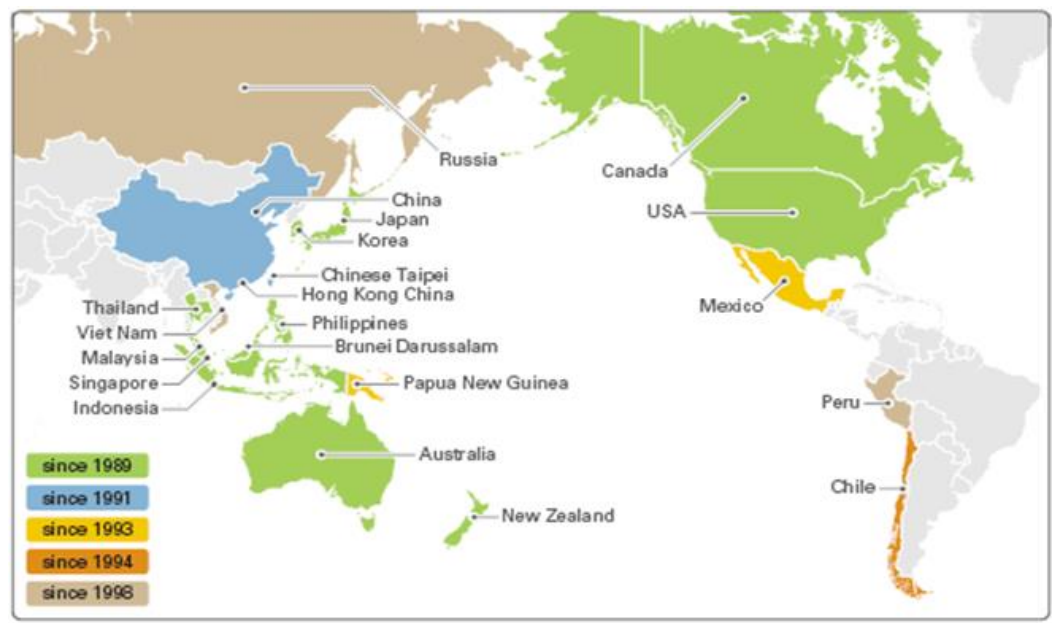

Fig. 1. APEC Twenty-one member economies

Beside the tangible damage and losses in Japan, it strongly impact the global markets of the supply chain interruption, especially from global supply chain viewpoint. In the 2011 earthquakes, the semi-conductor manufacturing and automobile industries were severely affected and interrupted in the Tohoku read in Japan. The consequences shown on the declining production in car industry. Comparing the number of car manufactured from February of 2011 (800,000), March $(400,000)$ and April $(290,000)$, the supply chain interruption shows the impact of the large-scale disaster toward Japan's global strategy on highly integrated operations. It may attributes to the declining of car productivity in Thailand (19.7\%), in the Philippines (24.0\%), and in Indonesia (6.1\%). Likewise, manufacturers involved in the global value chain such as computer, smartphone and ICT device faced shortage of essential chips produced or supplied by Japan.

Therefore, a trend of enhancing preparedness for private sector by adding new elements to BCP has become an essential issue of disaster management. In 2012, International Organization for Standardization has introduced the ISO 22301 as a new standard to regulate disaster management activities for business operations. An APEC survey conducted by the Asia Disaster Reduction Center shows that over $79 \%$ of companies including large corporations and SMEs that these companies neither didn't have nor know business continuity plans (BCPs), (see Fig. 2) [3]. From observation of the trend, obviously, the business owners think that the governments ought to take a major proportion of disaster management and responsible to help them reduce losses and overlook certain obligations shouldered by the business owners themselves. To better enhance the whole society disaster resilience, how to motivate active participation and border engage the involvement from private sectors are the essential backbone supporting to succeed the public-private partnerships. BCP with factors of natural hazards is an ideal vehicle to transport concepts of disaster risk reduction, capacity building and emergency preparedness to business operations via robust preparation.

The main purposes to introduce BCP to business are: 
1. Raise businesses' awareness and knowledge to develop disaster reduction/disaster preemptive mechanisms and responding teams.

2. Establish a process to help business develop tailor-made plan for solving foreseen challenges.

3. Help individual company in quickly resuming operation to strengthen business competitiveness and keep promises to clients and employees.

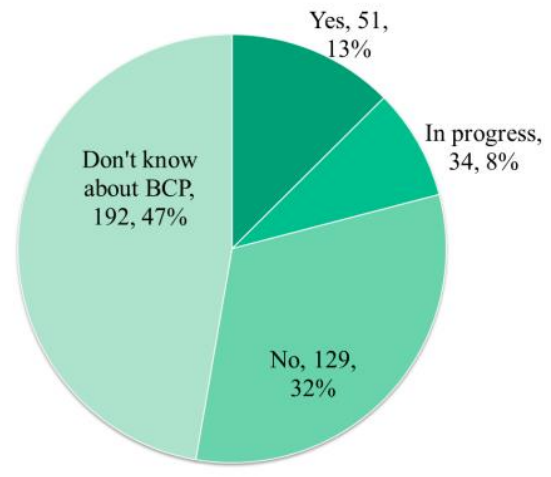

Fig. 2. Survey of adoption and awareness of BCP by the ADRC

More and more industries and corporations taking it seriously of the impacts brought by natural disasters as risks and threats to their employees, suppliers and customers after the 2011 earthquakes and tsunami in Japan. Hence, both public and private sectors recognize the importance of $\mathrm{BCP}$, which can help formulating plans on the potential risks and scenario to further identifying internal, and external vulnerabilities with disaster risk awareness while disasters to ensure the business continuity, industry development and economies sustainability.

\section{$3 \quad$ Primary Targets for Introducing Business Continuity}

Australia and Thailand co-host the 2010 "APEC Workshop on Public Private Partnerships and Disaster Resilience" address the need to develop a whole society approach on enhancing disaster resilience and outline the common objectives with scope of collaborative partnerships.

After the Great East Japan Earthquakes and Tsunami in 2011, the Asia Disaster Reduction Centre (ADRC) survey on 267 large and small-medium enterprises within 17 APEC member economies shows the averaged statistic of $67 \%$ - "Don't know about BCP" or "Don't have BCP". Exclude the large enterprises, the percentage for SMEs' jumps high to $83 \%$ [4]. With limited BCPs availability, the high disaster risk ranking of the economic activities, business operations and product manufacturing in the disaster-prone areas show the vulnerability of global supply chain while natural hazards. Without proper BCPs in positon to go through risk identification, preparedness, emergency response and business resumption phases, disaster can lead the situations toward 
business and supply chain interruptions and even cease to exist. Compare with those enterprises with BCPs, the quicker recovery from the disaster can quick resume the business operations, which contribute to the regional supply chain connectivity to uphold the regional economic sustainability. However, with limited risk awareness, local knowledge and disaster risk reduction capacity building or training program, business units tend not to prepare in advance. In views of business continuity after disasters, this research depict how to define the information source and utilize the communications tools (ICTs) to better raising the general risk awareness and enhancing disaster resilience as well as encouraging the public and private sectors to develop BCPs for managing risk or impact.

SMEs make great contributions to the national, regional and global economy and trade. Nevertheless, the SMEs are fragile in nature that hampered global supply chains and business operations while natural disasters especially large-scale ones. From coverage of news media, the repeating reports of SMEs' losses occupied headlines year after year. It highlights to some extent the natural disasters impact SMEs in great deal and induce severe supply chain interruption and aftermath economic losses.

A few tangible existing facts confirm the importance of disaster resilience to the SMEs' operations. Firstly, direct impacts of disasters can stop the whole or partial production lines' operations due to the facilities damages, raw materials contaminated or even workforce casualties. Secondly, accompany by the inconvenient situations for SMEs to recover while interruption on water/ electricity supply and transportations/ logistics occurred. Thirdly, indirect impacts on slow economic and livelihood recovery to some extent cripple business operations especially SMEs'.

Without doubts, flexibility is the key strength of SME to rapidly adapt to the changes of competitive marketplace. SMEs, compared to the large corporations, have relatively little and limited finical support, knowledge and human resource to cope with the risk and exposure to natural hazards. In global economic lifecycle, SME is the fundamental unit to contribute to the local community incomes and regional business economic growth. By reviewing other issues related to disaster management on public private partnership (PPP), disaster resilience and emergency preparedness, it is shown a common trend and demands of SME on mitigating potential disaster risk. As consequence, $\mathrm{BCP}$ is an ideal approach to linkage among business people, key stakeholders and disaster managers jointly to work on improving disaster resilience.

The ten easy steps for building up SME's BCP, developed base on ISO22301 Business Continuity Management Standard System, have been introduced to the Asia-Pacific region since 2012 by training workshops and document circulation. The ten steps are composed [5]:

1. Determine BCP purpose, scope and team.

2. Prioritized activities and Recovery Time Objective.

3. What do you need to resume key activities?

4. Risk assessment - know your tragic scenarios.

5. Do not forget pre-disaster protection and mitigation.

6. Emergency response to disaster.

7. BC Strategies to early resumption. 
8. Be financially prepared.

9. Exercise makes your plan functional.

10. Ongoing review and improvement.

\section{$4 \quad$ Integrated Big Data Sets for Coordinating Digital Preparedness for Natural Hazards}

Case studies from the recent large-scale disaster in the Asia Pacific clearly identify the emerging demands on big data and open data application in time of disasters for emergency preparedness. As a whole society from public services, private industries and general publics, a verified reliable information through the revolution concept of big data and open data is critical for formulating the dynamic DRR strategies and BCPs, deploying emergency relief missions, ensuring global supply chain resilience and maintaining quality growth and livelihoods security. Asia is one of the disaster-prone region, cross-border capacity building and training program, scenario-based drills and exercises on big data and open data on enhancing disaster-resilient manufacturing, trade and investment can direct benefit both of the regional economic sustainability and of human security.

Recent projects of business resilience and global chain resilience, conducted by APEC Small and Medium Enterprises Working Group (SMEWG) and APEC Transportation Working Group (TPTWG) respectively, emphasize importance of applying data and information for achieving smarter investments and building up safer trade environment. For twenty-one member economies of APEC to share the synergies of economic prosperity, regional capacity building and public-private partnership, it is vital to broadly adopt the big data and open data information sharing on emergency preparedness approach to concrete solid and sound foundation for global value/supply chain resilience to artery connect and support business and economic activities in the AsiaPacific region.

Digital preparedness is a cornerstone of evidence-based DRR approach, which offers value-added knowledge for emergent response while decision-making, process from big data and open data to information intelligence. However, there are technical and policy barriers for developing countries to utilized crowdsourcing, ICTs or Internet of Things (IoT) technology to build up an analytical database and integrated systems with proper telecommunication tools for cross-border BCPs or regional emergency preparedness from data collection to applications, especially for a cross-border or large-scale disasters. Taking into account of the diverse social-economic data sets of demographic characteristics, economic activities, educational background, gender, level of public awareness etc., it is essential to carefully interpret and identify the social vulnerability with gaps for enhancing regional capacity building as a whole society. These parameters from social science perspectives help capacity building at community level and reshaping actionable information from "big data and open data" approach for sustainable economic and business activities. 


\section{$5 \quad$ Best Practices on Digital Preparedness in Taiwan through Public-Private Partnership}

Taiwan is a highly disaster-prone country and how to mitigate disaster risk is an essential issue catching attentions from both government and the public. However, due to extreme weather events and potential large-scale earthquakes, risk exposures to land and population increase and become more diverse than ever. In past two decades, the Ministry of Science and Technology has been investing resources on fundamental scientific and technological researches related to characteristics of natural hazards and knowledge for disaster management that helps to pave the basis developing disaster risk reduction and emergency preparedness. Nowadays, emerging technologies speed up the telecommunications development and shorten the lead time from data to deliverable messages in the digital age. In information age, big data and open data not just facilitate trades and business, but also benefit disaster management as a whole.

In case of the lessons learnt from the 2011 Great Japan Earthquakes and Tsunami, specific big datasets can provide a dynamic view on human behaviors and reactions to the shakings and warnings as well as the traffic flow in different phases. From Predisaster to post disaster phase, from data to reliable information or message is critical for raising public awareness. An updated information with better risk communication approaches can mitigate the disturbance while emergency respond and level up the quality DRR assessments with higher public awareness of emergency situations. Applying open data principles to big data, it will enhance social preparedness and resilience. Since 2013, Taiwan has introduced the Common Alerting Protocol (CAP) to standardize disaster information for dissemination though multiple channels. Google Crisis Map is one of the platforms in building up the last mile to connect people living in Taiwan and one of the easy access tools to adopt in sending the demanding information in times of disasters. Later, in 2016, five system operators of the fourth-generation (4G) telecommunications officially join to provide the Cell Broadcasting Service (CBS) to mobile phone users. It is an innovative approach to facilitate raising public awareness and ensure wide coverage of the dissemination of information during emergency with in time collaborations among public and private sectors.

In 2009, Typhoon Morakot brought record-breaking rainfalls which caused massive floods and large-scale landslides in the southern Taiwan. The tremendous casualties and losses pushed forward a restructure of disaster management framework and the full commitment of improving emergency operation via information integration. The improvement on meeting the quality information demands for decision-making required to tackle of what we have been exposed to when Typhoon Morakot strike - no adequate collaborations and synergies among respective governmental agencies and authorities at all level to disseminate and interpret the just-in-time effective integrated information for proactive emergency preparedness and response.

One of the key reasons for formulating an integrated information framework on decision-making support is that too many existing individual systems operated independently by each government authority and provided only fragment of information in different time span. Hence, an efficient coordinated emergency preparedness and re- 
sponse countermeasure cannot be deployed in time without the holistic views and pictures of the real situations and the impact assessments on Typhoon Morakot prior to the disasters hit. To cope with the incompatibility of data sets, file structures and valueadded information via the social media related to typhoons, floods and precipitationtriggered landslides, the remedial countermeasures request decisive decisions to acquired and incorporated science and technology efforts for integration - 'one Taiwan one respond'. The evidence-based emergency operation needs the implementation of applying improved numerical ensemble models to forecast trajectories and rain of typhoons, producing potential risk maps of inundation for scenario simulation, integrating real-time monitoring data for further decision making. All the outcomes and collective verified information are displayed on GIS-Web-based platform for discussion and decision-making at all level of the government authorities and Emergency Operation Centers (EOCs). Without doubts, big data is the core behind the scene to support the emergency preparedness and operations.

In recent years, the scope of information sharing has extended from central to local governments and NGOs to help enhancing information preparedness at grassroots levels. For local governments, delayed or inadequate information hampers and slows down the process of decision making. Information dissemination and sharing from central to local governments fill in the gap of miss-links information and provides a common operation picture to bring meaningful discussions-speak on the same page. Collaborations with NGOs on helping them to allocate resources in advance, governments can benefit from receiving the NOGs feedbacks as the reliable on-site data source for information and data collection. The mechanism of big data integration is shown in Fig.3[6].

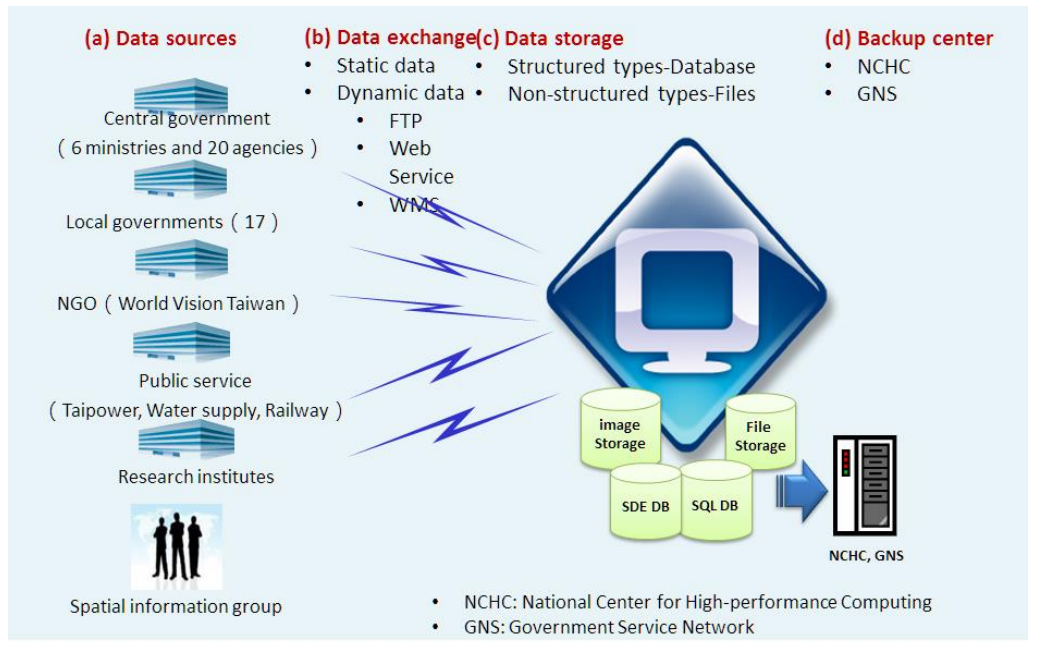

Fig. 3. Integration mechanism of big data [6].

It is always a challenging question to answer - how many and where are people staying - or - when will the next destructive earthquakes hit? For the number of the affected people, through an averaged estimation of population distribution, allocating population proportional to floor areas based on census statistics and taxation data could 
calculate it. However, it presents a static status of population distribution but real time facts, which does not fully reflect people's dynamic movements in urban districts or national wide around the clock while disasters. As scenario analysis for seismic risk reduction in urban areas, locations, population density and distribution are the key factors, which shape the strategic approaches on how to mitigate possible casualties claimed by a large-scale earthquake.

To resolve the situation, National Science and Technology Center for Disaster Reduction (NCDR) collaborated with the Chunghwa Telecom (CHT), a major telecom service provider occupies $37.90 \%$ of the mobile service in Taiwan [7], to tracing mobile signals for collecting numbers of mobile users at specific grids to estimate population distribution pattern. The scope of the pilot project covers three major metropolitan areas in north Taiwan, Taipei City, New Taipei City and Keelung City with numbers of population at 2,695,007, 3,959,855 and 373,721 respectively. The CHT provides data updates three times; at $9 \mathrm{am}$, at $3 \mathrm{pm}$ and $9 \mathrm{pm}$; every day that roughly reflects dynamic characteristics of urban population flow and allocation pattern in the urban area as illustrated in the Fig. 4.

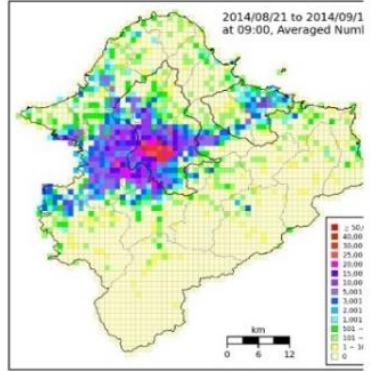

(a) Averaged data at 9 am

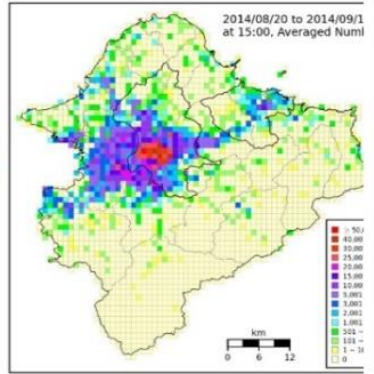

(b) Averaged data at $3 \mathrm{pm}$

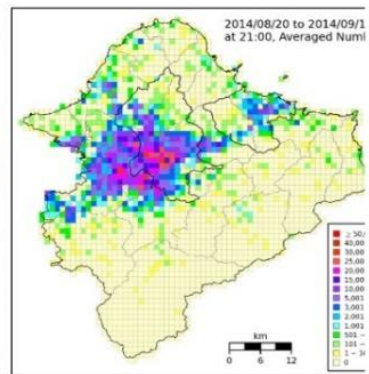

(c) Averaged data at $9 \mathrm{pm}$

Fig. 4. Population distribution based on the CHT data

\section{Channels of Disaster Information Dissemination - 7-ELEVEN, Convenience Chain Stores}

The Office of Disaster Management launched a project since late 2011 to recruit convenience chain stores for undertaking the roles of situation reporting and information dissemination if disasters. The aim is to provide easy access to the up-to-dated information if emergencies and to facilitate the efficiency and effectiveness of emergency response at township level. The Uni-President Corporation, the holding company of 7-ELEVEN in Taiwan, is the first one of the partners to join the above-mentioned project. Uni-President, one of the largest consumer product manufacturers, runs 7 -ELEVEN chain stores numbering over 4,800 retail outlets with comparably wide coverage of in-land logistics networking in Taiwan.

To facilitate the efficient and effective information dissemination, each 7-ELEVEN is well equipped with a LCD panel at cashier displayed possible risks or threats with 
relevant emergency information on site at local level as illustrated in the Fig. 5. During the 2012 typhoon season (usually from May to October), 7-ELEVEN has piloted a successful story on public private partnership. Their customers including drop-by tourists are well informed and benefit from the real-time typhoon and weather related information via these LCD panels to avoid the possible impact on floods in the immediate areas. In the case of floods, the person in charge of the disaster reporting at 7-ELEVENs will direct report their observations on water levels in real-time basis to the Water Resource Agency(WRA), the government authority of floods. The WRA will relay the confirmed flood cases to the emergency operation center at central or local level for further emergency response i.e. road closure or search and rescue (SAR) deployment.

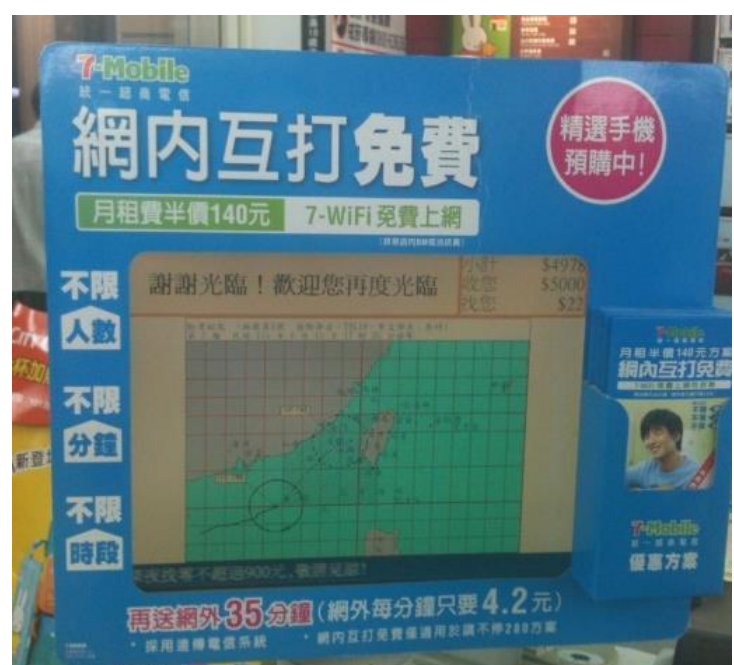

Fig. 5. Updates on Typhoon displayed on 7-ELEVEN LCD Panel

\section{Open Data on the Common Alerting Protocol (CAP)}

For further expand coverage on information dissemination during typhoon season, Google starts to offer its services on displaying and disseminating the real-time warning messages by Google Crisis Map, Google Alerts and Google Now. The data sources of warning messages, follow the CAP - an international standard, are come from nine government authorities and public transportation servicing sectors. Messages in CAP format are open to the internet service providers, APP developers, research institutes and industries as open data for them further develop disaster related researches/systems or the innovative DRR APPs and etc. from the free-of-charge information.

Smartphone is another ideal handy device to catch warning messages in the sense of point to point and end to end services, direct to the end users concept. With introducing the $4 \mathrm{G}$ mobile technique, a cell broadcasting system (CBS) project is ongoing to send alerts and warnings by the Public Warning System (PWS), which put through the sound 
of the sirens or alarms as top priority emergency messages from Mobile Network Operator (NNO) to the smartphone users, if earthquakes or any immediate emergency.

\section{Conclusion to Move Forward - Enhancing Digital Preparedness on Natural Hazards for Sound and Smarter Investments}

The cross-border movements of goods, services and workforce grow rapidly and rather dynamically in the Asia-Pacific. The natural disaster warnings and alerts from big data and open data approach can provide the best and holistic common pictures to effectively integrate the information flow with partnership between public and private sectors to mitigate the impacts. For particularly note, the newly emerging technology accelerate the development of telecommunications technology and shortens the lead time of data processing and information dissemination. Wide coverage of disaster related information dissemination contributes by social media, 7-Eleven chain store, smartphone, MNO etc. In the digital age, big data and open data approach plays the key role in saving lives, securing livelihood, facilitating trade and investments, enhancing business resiliency in operations, raising disaster risk awareness for better emergency preparedness, formulating business continuity plan, maintaining resilient global supply chain, protecting critical infrastructure and safeguarding tourism industries.

In the case of the 2011 Great Japan Earthquakes and Tsunami, Using proper big datasets can facilitate interpret human behaviors and reactions to provide more comprehensive pictures and views to the shakings, warnings efficiencies and the traffic flow situation in different phases of disasters. From Pre-disaster to post-disaster phases, big data and open data approach can deliver just in time message to maintain the effective and efficient risk communication with higher level of public awareness through public private partnership to deploy emergency response effort and to deliver quality DRR assessments if situations.

APEC for a studies conclude the emergent needs to adopt big data and open data approach on large scale disaster with cross-border view of digital preparedness while emergency. To include whole society from public sectors to private industries and general publics, a comprehensive picture for emergency response using real time big data and open data is vital to succeed the collaborative interoperability operations from adopting DRR strategies, BCPs, deploying emergency relief missions and mitigating losses for sustainable economic growth and human security. A disaster-prone region, regional capacity building programs and training on BCPs and promoting big data and open data approach can ensure safer and smarter cross-border trades and investments in the booming economies of Asia.

The core value of the key objectives on enhancing digital preparedness against natural disasters is the real-time information sharing and interoperability with crossborder capacity building on crosscutting demands with synergies. The objectives are shown as below: 
1. To picture the capacity building among APEC member economies in adopting big data and open data approach to build up a foundation for information sharing mechanism;

2. To interpret on-demand big data and open data through a region-wide survey to further identify shortfalls, challenges and opportunities that public and private sectors concerned the most;

3. To promote big data and open data approach to provide safer marketplace and enhance global supply chain resilience through quality BCPs, transparent real-time risk information disclosure and resilient critical infrastructure protection plan in position;

4. To formulate a collaborative real-time focal point network and mechanism on sharing cross-border big data and open data on better emergency preparedness to facilitate integrated actions and capacity building on DRR at regional level as a whole society.

Introducing science-and-technology based sharing mechanism through ICTs to enhance BCPs and digital preparedness on DRR is a global trend as the SFDRR highlighted in the third WCDRR. Without doubts, a solid backbone support via ICTs can benefit the stakeholders with synergy in all phases of disaster management from mitigation, preparedness, response to recovery in the Asia-Pacific region.

\section{References}

1. EM-DAT International Disaster Database, http://www.emdat.be/database.

2. Asia-Pacific Economic Cooperation's Stats APEC, Key Indicators Database and Bilateral Linkages Database, November 2011.

3. Asian Disaster Reduction Center (ADRC), A Better Understanding of the Current Status of BCP Adoption and the Level of BCP Awareness among Private Sector SMEs in the APEC Region, 2011.

4. Source: Asian Disaster Reduction Center (ADRC).

5. Guidebook on SME Business Continuity Planning, http://publications.apec.org/publicationdetail.php?pub_id=1449/

6. Source: National Science and Technology Center for Disaster Reduction (NCDR).

7. Chunghwa Telecom Operation Report - the 1st Quarter, 2016 TSE: 2412 NYSE: CHT April 28, 2016, http://www.cht.com.tw/ir/upload/content/20160428_1Q2016_presentation_CH_final.pdf

8. APEC Emergency Preparedness Working Group, http://www.apec.org/groups/somsteering-committee-on-economic-and-technical-cooperation/working-groups/emergencypreparedness.aspx

9. APEC Emergency Preparedness Working Group, In the category of 2011 outcomes of activities, http://www.apec-epwg.org/

10. APEC SME Crisis Management Center, Multiple-year Project on Disaster Resilience Building for SMEs in APEC, 2011. (M SCE 02/2011A_Improving Natural Disaster Resilience of APEC SMEs to Facilitate Trade and Investment)

11. Completion Report of Multi-Year Project: Improving Natural Disaster Resilience of APEC SMEs to Facilitate Trade and Investment, http://www.apec-epwg.org/public/uploadfile/act/2c0ca0199ba34676c3a21032d8e03918.pdf 